\title{
The characteristics and risk factors for common psychiatric disorders in patients with cancer seeking help for mental health
}

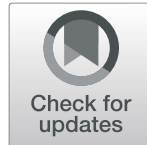

\author{
Dilek Anuk ${ }^{1 *}$, Mine Özkan ${ }^{1}$, Ahmet Kizir ${ }^{2}$ and Sedat Özkan ${ }^{1}$
}

\begin{abstract}
Background: Although the adverse effects of cancer diagnoses and treatments on mental health are known, about less than $10 \%$ of patients are estimated to be referred to seek help. The primary purpose of this study was to obtain the baseline information on patients with cancer seeking help for mental health who presented for the first time to the psycho-oncology outpatient clinic, and to identify risk factors that may provide clues healthcare practitioners in recognizing those needing psychological help in oncology practice.
\end{abstract}

Methods: We reviewed the charts of 566 patients with cancer who were referred to the psycho-oncology outpatient clinic over a two-year period. The study includes the socio-demographic data, illness characteristics, psychiatric characteristics, psychiatric diagnoses, and treatment recommendations for these patients.

Results: The incidence of diagnoses of psychiatric disorders was $97.5 \%$. The distributions of psychiatric diagnoses were as follows: any kind of adjustment disorders, mood disorders, anxiety disorders, organic brain syndrome, personality disorders, delusional disorder, and insomnia. Recurrence of cancer, other chronic medical illnesses, a history of psychiatric disorders, poor social support, and low income comprised the common significant risk factors for adjustment disorders, mood disorders, and anxiety disorders. These risk factors were also seen to be significant in the regression analysis in terms of sex.

Conclusion: This study identifies the distribution of psychiatric disorders, the risk factors for specific psychiatric disorders, and draws attention to the fact that there are serious delays in patients seeking psychiatric help and in the referrals of oncologists for psychological assessment. Identifying risk factors and raising oncologists' awareness toward risk factors could help more patients gain access to mental health care much earlier.

Keywords: Help-seeking, Mood disorders, Adjustment disorders, Anxiety disorders, Psycho-oncology, Outpatients, Recurrence

\section{Background}

Cancer is the leading cause of deaths in developed countries and second after heart disease in developing countries [1]. Despite improvements in treatment, cancer is still believed to have a high mortality rate, and is considered to have an inherent potential for death, suffering and pain, causing considerable psychological distress, even in patients with a high recovery rate [2]. Its diagnosis poses a crisis requiring the patient to comply with a number of

\footnotetext{
* Correspondence: dilekanuk@yahoo.com

'Department of Consultation Liaison Psychiatry, Department of Psychiatry, Istanbul Faculty of Medicine, Istanbul University, Capa, 34390 Istanbul, Turkey Full list of author information is available at the end of the article
}

tremendous challenges. While trying to make serious treatment decisions, patients try to cope with intense emotional stress [3]. The emotional distress includes the diagnosis of a life-threatening illness, aggressive medical treatment, changes in lifestyle or direct effects of the tumor itself, lack of family support system, personality traits, familial conflicts, and economic problems [4-6].

The incidence of psychological disorders in patients with cancer is very high (30-60\%) [7-9], with approximately $29-43 \%$ fulfilling the diagnostic criteria for psychiatric disorders $[10,11]$. The most commonly encountered mental problems encompass depressive symptoms associated with mixed anxiety and adjustment 
disorder or depressive mood or major depression [7, 11]. Razavi et al. identified $47 \%$ of psychiatric diagnoses of those attending both outpatient and inpatient departments [12]. Kissane et al. showed that psychiatric diseases were diagnosed in $73 \%$ ( $24 \%$ systemic family problems, $23 \%$ mood disorders, $16 \%$ adjustment disorders, and 10\% organic mental disorders) of 271 patients with cancer referred to Consultation Liaison Psychiatry [13]. A total of 765 patients with cancer referred to a psycho-oncology unit in Japan had diagnoses of psychiatric diseases, 59 (6\%) of whom were outpatient patients, including adjustment disorders (24\%), delirium (16\%), and major depressive disorder (12\%) [10].

Left untreated, psychological distress would lead to long-term devastating consequences with regard to noncompliance with treatment [14], low survival rates [15], desire to accelerate death [16], and poor quality of life for both patients and their relatives $[17,18]$.

Although adverse effects of cancer diagnoses and treatments have long been recognized, it is estimated that less than $10 \%$ of patients are referred to seek psychological help [19]. The primary purpose of this study was to obtain baseline information on psychological help-seeking in patients with cancer who presented for the first time to the psycho-oncology outpatient clinic.

The answers to two crucial research questions were sought:

- What were the socio-demographic, cancer-related as well as psychiatric characteristics of patients with cancer seeking help who presented to the psychooncology outpatient clinic?

- What were both the overall and sex-based risk factors in the development of mood disorders, adjustment disorders, and anxiety disorders in those patients?

\section{Methods \\ Design}

This study was conducted at the Oncology Institute of Istanbul University, one of the leading hospitals in the field in Turkey where, on average, 5000 new patients present per year and 60,000 patients are followed up at 3, 6 months, and 12 months after treatment. Patients with cancer and their relatives receive psychiatric and psychological treatment services at the Istanbul University Consultation Liaison Psychiatry Department. A multidisciplinary team (2 psychiatrists, 1 psychologist) provides this service at the psycho-oncology outpatient clinic in the Oncology Institute building, with about 800 (inpatient and outpatient) patients annually. This is an exploratory study with a retrospective chart review design. We reviewed the charts of 566 patients with cancer who were referred to the psycho-oncology outpatient clinic from January 2015 to February 2017. The sociodemographic data, psychiatric characteristics, psychiatric diagnoses, and treatment recommendations in the patients' charts were assessed. Data on the diseases and psychiatric diagnoses were established based on the Diagnostic and Statistical Manual of Mental Disorders, 4th Edition (DSM-IV-TR) [20]. The study was reviewed and approved by the institutional review boards at the Oncology Institute of Istanbul University in terms of ethics (No: 709731125-604.01.01). Due to the fact that the study was designed as a retrospective analysis and we only reviewed the patients' charts without performing interviews or direct evaluations with the patients, it was not necessary to obtain written consent from the patients. All patients' records were anonymized and de-identified prior to analyses.

\section{Data analyses}

The statistical analysis was performed using the SPSS 21.0 statistical package program. The demographic and clinical data of the participants were analyzed using descriptive statistics. Pearson's Chi-square test and Fisher's exact test were used for the comparison of qualitative data. Logistic regression analysis was used to examine the risk factors for adjustment disorders, mood disorders, and anxiety disorders. A regression analysis model was developed including the sociodemographic characteristics (age, sex, education, income level, occupation), medical conditionrelated characteristics (duration of illness, presence of recurrence, presence of metastasis, presence of secondary cancer, and other chronic illnesses), and psychiatric variables (social support, history of psychiatric disorders or family history of psychiatric disorders) to identify significant risk factors for the three psychiatric groups, i.e. mood disorders, adjustment disorders, and anxiety disorders. Regression analysis was first performed for all patients and then for the sexes using the same model excluding sex. In the logistic regression analysis, variables were selected by the enter method and the risk ratios [odds ratio (OR)] were calculated by taking the first categories as references. The results were assessed at 95\% confidence intervals, and $p<0.05$ as the significance level. Only significant risk factors are included in the tables in the regression analysis.

\section{Results \\ Sociodemographic and Cancer-related characteristics of help-seeking patients}

The rate of women presenting to the psycho-oncology outpatient clinic (62\%) was higher than for men (38\%) $\left(x^{2}: 32.678 / p<0.001\right)$. The mean age of the women was $49.62 \pm 13.4$ years, which was statistically significantly lower than in the men $(53.83 \pm 16$ years) (t: $3.370, p=$ 0.001). Of the patients, $76 \%$ were married and $90.5 \%$ were living in nuclear family conditions. The educational 
status was as follows: mostly secondary school graduates (55.5\%) and literate / elementary school graduates (33.2\%), and college graduates (11.3\%); $37.5 \%$ were housewives, $31.1 \%$ were retired, $26.9 \%$ were working, and $4.6 \%$ were students. Three-quarters $(76 \%)$ of the patients had middle-income status, $51.1 \%$ had poor social support, $82.7 \%$ lived in urban areas, and all benefited from social security services.

The oncologic diseases, which lasted between 1 month and 240 months (Mean \pm SD: $22.3 \pm 33.1$ months), included breast cancer (31.1\%), lung cancer (11.1\%), gastrointestinal cancers (12.4\%), head and neck cancer (16.6\%), and gynecologic cancers (9.9\%). Metastatic involvement was present in $22.6 \%$ of the patients, $20.1 \%$ had cancer recurrence, and $2.8 \%$ had secondary cancer. Of all patients, $20 \%$ also had chronic medical illnesses such as diabetes and hypertension, and their first-degree relatives $(14.5 \%)$ had had any type of cancer diagnosis (Table 1).

\section{Psychiatric characteristics and distribution of diagnoses}

The majority $(81.6 \%)$ of the patients were referred by attending oncologists, $9.5 \%$ were brought by family members, and $8.8 \%$ presented on their own to the outpatient department of psycho-oncology. Sleep problems, irritability, tendency to cry easily, sadness, and pain were among the leading symptoms at baseline. Women reported sleep problems, tendency to cry easily, irritability, pre-occupation with the illness, and sadness as the first five most frequent issues, and men reported sleep problems, irritability, pain (usually incompatible with their medical conditions), sadness, and tendency to cry easily as the most frequent problems (Table 2).

The rate of psychiatric diagnoses was $97.5 \%$ and the distribution of psychiatric diagnoses was as follows: any kind of adjustment disorders (65\%), mood disorders (18\%), anxiety disorders $(9.7 \%)$, organic brain syndrome (1.4\%), personality disorders (1.4\%), delusional disorder (1.2\%), and insomnia $0.9 \%$. The comorbid diagnosis was made in $2.1 \%$ (depression accompanied by anxiety disorder). Only $2.5 \%$ of the patients had no psychiatric diagnosis. Previous psychiatric treatment had been received by $7.6 \%$ of the patients, and $0.7 \%$ had a family history of mental illnesses. Just under half (48.9\%) of patients had adequate social support, $51.1 \%$ poor social support (Table 2).

\section{Risk factors for mood disorders, adjustment disorders, and anxiety disorders}

Significant risk factors for diagnosis of mood disorders included recurrence of cancer, other chronic medical illnesses, history of psychiatric disorder, secondary cancer presence, metastasis, poor social support, low income level, being single or divorced, and low educational level. This model explained $57 \%$ of the total variance, being useful to predict the evolution of mood disorders (Table 3).

Significant risk factors for adjustment disorders covered cancer recurrence, having other chronic medical illnesses, history of psychiatric disorder, the duration of illness less than 1 year, cancer history in family members, low income level, poor social support, and being single or divorced. This model explained that adjustment disorders accounted for $28 \%$ risk factors for patients, which is useful to predict the evolution of adjustment disorders (Table 3).

The risk factors identified for anxiety disorders were as follows: recurrence of cancer, presence of secondary cancer, having another chronic medical illness, history of psychiatric disorder, duration of illness less than 1 year, low income level, and poor social support. This model identified $29.5 \%$ of risk factors for patients diagnosed with anxiety disorders (Table 3 ).

\section{Risk factors according to sex for mood disorders, adjustment disorders, and anxiety disorders}

For female cases, significant risk factors that increased the mood disorders were recurrence, presence of secondary cancer, other chronic medical illnesses, history of psychiatric disorder, low income level, poor social support, and being single or divorced. The model accounted for $49 \%$ of the risk factors for women diagnosed as having mood disorders. When the risk factors related to adjustment disorders in female cases were examined, recurrence, metastasis, history of psychiatric disorder, presence of other chronic medical illnesses, low income level, poor social support, and the duration of illness less than 1 year were significant risk factors that increased the likelihood of being diagnosed as having adjustment disorders. These results revealed risk factors for $25.6 \%$ of women diagnosed as having adjustment disorders. The significant risk factors that increased the likelihood of being diagnosed as having anxiety disorder were recurrence, metastasis, presence of other chronic medical illness, history of psychiatric disorder, the duration of illness less than 1 year, low income level, and poor social support. These results accounted for 30\% of women diagnosed with anxiety disorders in terms of risk factors (Table 4).

Significant risk factors that increased the likelihood of being diagnosed with mood disorders in male patients were recurrence, presence of secondary cancer, other chronic medical illness, history of psychiatric disorder, metastasis, being single or divorced, poor social support, and low income level. The model explained $71.5 \%$ of risk factors for men diagnosed as having mood disorders. When the risk factors for adjustment disorders in male patients were examined, low income level, recurrence, cancer history in family members, and history of psychiatric disorder were identified as significant risk factors 
Table 1 Sociodemographic and cancer-related characteristics of help-seeking patients

\begin{tabular}{|c|c|c|}
\hline \multicolumn{3}{|l|}{ Age (years): Mean \pm SD (Range) } \\
\hline Overall Patients & \multicolumn{2}{|c|}{$51.22 \pm 14.55(16-8$} \\
\hline Female (t: $3.370, p=0.001)$ & \multicolumn{2}{|c|}{$49.62 \pm 13.4(16-85$} \\
\hline \multirow[t]{2}{*}{ Male } & \multicolumn{2}{|c|}{$53.83 \pm 16(16-87)$} \\
\hline & $n$ & $\%$ \\
\hline \multicolumn{3}{|l|}{ Sex } \\
\hline Female $\left(x^{2}: 32.678 / p<0.001\right)$ & 351 & 62 \\
\hline Male & 215 & 38 \\
\hline \multicolumn{3}{|l|}{ Education level } \\
\hline Literate / elementery school & 314 & 55.5 \\
\hline Secondary school graduates & 188 & 33.2 \\
\hline College & 64 & 11.8 \\
\hline \multicolumn{3}{|l|}{ Marital status } \\
\hline Married & 430 & 76 \\
\hline Single & 59 & 10.4 \\
\hline Divorced/Widowed & 77 & 13.6 \\
\hline \multicolumn{3}{|l|}{ Employment } \\
\hline Housewife & 212 & 37.5 \\
\hline Working fulltime & 152 & 26.9 \\
\hline Retired & 176 & 31.1 \\
\hline Other & 26 & 4.6 \\
\hline \multicolumn{3}{|l|}{ Income level } \\
\hline Low & 120 & 21.1 \\
\hline Middle & 430 & 76 \\
\hline Upper & 16 & 2.8 \\
\hline \multicolumn{3}{|l|}{ Type of family } \\
\hline Core & 512 & 90.5 \\
\hline Extended & 40 & 7.1 \\
\hline Alone & 14 & 2.5 \\
\hline \multicolumn{3}{|l|}{ Cancer site } \\
\hline Breast & 176 & 31.1 \\
\hline Lung & 63 & 11.1 \\
\hline Gastrointestinal cancers & 70 & 12.4 \\
\hline Head and neck cancer & 64 & 11,3 \\
\hline Brain tumors & 30 & 5.3 \\
\hline Gynecologic cancers & 56 & 9.9 \\
\hline Male genitourinary cancers & 29 & 5.1 \\
\hline Leymphoma & 36 & 6.4 \\
\hline Malignant melanoma /skin cancer & 12 & 2.1 \\
\hline Bone and soft tissue cancer & 17 & 3 \\
\hline Other & 13 & 2.3 \\
\hline \multicolumn{3}{|l|}{ Stage } \\
\hline Local disease & 315 & 55.7 \\
\hline Locoregional recurrence & 114 & 20.1 \\
\hline
\end{tabular}

Table 1 Sociodemographic and cancer-related characteristics of help-seeking patients (Continued)

\begin{tabular}{|c|c|c|}
\hline Metastatic & 128 & 22.6 \\
\hline Unknown & 9 & 1.6 \\
\hline \multicolumn{3}{|l|}{ Oncological treatment } \\
\hline $\begin{array}{l}\text { Surgery+chemotherapy+ radiotheraphy } \\
\text { (+hormone therapy) }\end{array}$ & 182 & 32.2 \\
\hline Surgery+chemotherapy & 112 & 19.8 \\
\hline Chemotherapy+ radiotheraphy & 85 & 15 \\
\hline Chemotherapy & 76 & 13.4 \\
\hline Surgery+radiotheraphy & 51 & 9 \\
\hline Radiotheraphy & 19 & 3.4 \\
\hline Surgery+chemotherapy+hormone therapy & 16 & 2.8 \\
\hline Surgery & 12 & 2.1 \\
\hline Surgery +interferon & 3 & 0.5 \\
\hline Treatment is not yet started & 4 & 0.7 \\
\hline Other & 9 & 1.6 \\
\hline \multicolumn{3}{|l|}{ Any other medical illnesses } \\
\hline Yes & 113 & 20 \\
\hline No & 453 & 80 \\
\hline \multicolumn{3}{|l|}{ Family history of cancer } \\
\hline Yes & 82 & 14.5 \\
\hline No & 484 & 85.5 \\
\hline \multicolumn{3}{|l|}{ Secondary cancer } \\
\hline Yes & 16 & 2.8 \\
\hline No & 550 & 97.2 \\
\hline Duration of cancer (month): Mean \pm SD (Range) & \multicolumn{2}{|c|}{$22.3 \pm 33.1(1-240)$} \\
\hline
\end{tabular}

for adjustment disorders. The model defined $38.4 \%$ of risk factors in men diagnosed as having adjustment disorders. For men with the diagnosis of anxiety disorders, low income level, and recurrence or the presence of secondary cancer were identified as significant risk factors. The model explained the risk factors of 30\% of men diagnosed as having anxiety disorders (Table 4).

\section{Discussion}

Offering mental health services to patients with cancer is becoming an integral part of oncologic treatments because psychological problems have an adverse effect on cancer management. The main aim of this study was to provide a comprehensive description of baseline information on patients with cancer seeking help for mental health and to define the overall and sex-specific risk factors for the 3 main diagnostic groups (mood disorders, adjustment disorders, anxiety disorders) at the outpatient psycho-oncology clinic over a 2-year period.

The rate of women who presented to the outpatient department of psycho-oncology was determined to be significantly higher than for men (Table 1). The number of 
Table 2 Psychiatric characteristics of the patients

\begin{tabular}{|c|c|c|c|c|c|c|}
\hline & \multicolumn{2}{|c|}{ Female } & \multicolumn{2}{|c|}{ Male } & \multicolumn{2}{|c|}{ Total } \\
\hline & $n$ & $\%$ & $\mathrm{n}$ & $\%$ & $n$ & $\%$ \\
\hline \multicolumn{7}{|l|}{ Who is requesting the application } \\
\hline By the oncologists & 293 & 83.5 & 169 & 78.6 & 462 & 81.6 \\
\hline By ownself & 41 & 11.7 & 9 & 4.2 & 50 & 8.8 \\
\hline By family members & 17 & 4.8 & 37 & 17.2 & 54 & 9.5 \\
\hline \multicolumn{7}{|l|}{ Referral symptoms } \\
\hline Sleep problems & 92 & 26.2 & 84 & 39.1 & 176 & 31.1 \\
\hline Tendency to cry easily & 74 & 21.1 & 26 & 12.1 & 100 & 17.7 \\
\hline Irritability / intolerance & 67 & 19.1 & 56 & 26 & 123 & 21.7 \\
\hline Despondency & 48 & 13.7 & 27 & 12.6 & 75 & 13.3 \\
\hline Pre-occupation with illness & 63 & 17.9 & 22 & 10.2 & 85 & 15 \\
\hline Trouble / restlessness & 35 & 10 & 26 & 12.1 & 61 & 10.8 \\
\hline Pessimism & 14 & 4 & 6 & 2.8 & 20 & 3.5 \\
\hline Olm / metastasis / fear of recurrence & 14 & 4 & 4 & 1.9 & 18 & 3.2 \\
\hline Palpitations, fainting sensation & 14 & 4 & 2 & 0.9 & 16 & 2.8 \\
\hline Marital problem & 25 & 7.1 & 2 & 0.9 & 27 & 4.8 \\
\hline Pain & 41 & 11.7 & 29 & 13.5 & 70 & 12.4 \\
\hline Inability to enter MR or the radiotherapy device & 16 & 4.6 & 9 & 4.2 & 25 & 4.4 \\
\hline Concern & 39 & 11.1 & 16 & 7.4 & 55 & 9.7 \\
\hline Unhappiness & 12 & 3.4 & 7 & 3.3 & 19 & 3.4 \\
\hline Precision / obsession & 4 & 1.1 & 1 & 0.5 & 5 & 0.9 \\
\hline Forgetfulness & 7 & 2 & 6 & 2.8 & 13 & 2.3 \\
\hline Body image problems & 14 & 4 & 5 & 2.3 & 19 & 3.4 \\
\hline Control of a previously started drug & 6 & 1.7 & 4 & 1.9 & 10 & 1.8 \\
\hline Getting newly cancer diagnosis & 3 & 0.9 & 3 & 1.4 & 6 & 1.1 \\
\hline Treatment rejection & 3 & 0.9 & 5 & 2.3 & 8 & 1.4 \\
\hline Request for support & 12 & 3.4 & 2 & 0.9 & 14 & 2.5 \\
\hline Other & 6 & 1.7 & 6 & 2.8 & 12 & 2.1 \\
\hline No complaints & 11 & 3.1 & 13 & 6 & 24 & 4.2 \\
\hline \multicolumn{7}{|l|}{ Psychiatric Diagnosis } \\
\hline \multicolumn{7}{|l|}{ Anxiety disorders } \\
\hline Anxiety disorder & 19 & 5.4 & 8 & 3.7 & 27 & 4.8 \\
\hline Common anxiety disorder & 9 & 2.6 & 4 & 1.9 & 13 & 2.3 \\
\hline Panic disorder & 2 & 0.6 & 1 & 0.5 & 3 & 0.5 \\
\hline The claustrophobia & 4 & 1.1 & - & - & 4 & 0.7 \\
\hline Obsessive-compulsive disorder & 1 & 0.3 & - & - & 1 & 0.2 \\
\hline Somatoform Disorder & 5 & 1.4 & 2 & 0.9 & 7 & 1.2 \\
\hline \multicolumn{7}{|l|}{ Mood disorders } \\
\hline Depression & 58 & 16.5 & 27 & 12.6 & 85 & 15 \\
\hline M depression + obsessive compulsive disorder & 5 & 1.4 & - & - & 5 & 0.9 \\
\hline M depression + generalized anxiety disorder & 3 & 0.8 & 4 & 1.9 & 7 & 1.2 \\
\hline Complicated grief reaction & 2 & 0.6 & - & - & 2 & 0.4 \\
\hline Bipolar disorder & 2 & 0.6 & - & - & 2 & 0.4 \\
\hline
\end{tabular}


Table 2 Psychiatric characteristics of the patients (Continued)

\begin{tabular}{|c|c|c|c|c|c|c|}
\hline & \multicolumn{2}{|c|}{ Female } & \multicolumn{2}{|c|}{ Male } & \multicolumn{2}{|c|}{ Total } \\
\hline & $n$ & $\%$ & $\mathrm{n}$ & $\%$ & $n$ & $\%$ \\
\hline \multicolumn{7}{|l|}{ Adjustment Disorders } \\
\hline Anxious adjustment disorder & 112 & 31.9 & 94 & 43.7 & 206 & 36.4 \\
\hline Depressive adjustment disorder & 94 & 26.8 & 49 & 22.8 & 143 & 25.2 \\
\hline Mixt adjustment disorder & 16 & 4.6 & 3 & 1.4 & 19 & 3.4 \\
\hline Delirium & 2 & 0.6 & 6 & 2.8 & 8 & 1.4 \\
\hline Insomnia & 1 & 0.3 & 4 & 1.9 & 5 & 0.9 \\
\hline Personality disorder & 3 & 0.9 & 5 & 2.3 & 8 & 1.4 \\
\hline Delusional disorder & 4 & 1.1 & 3 & 1.4 & 7 & 1.2 \\
\hline No complaints & 9 & 2.6 & 5 & 2.3 & 14 & 2.5 \\
\hline \multicolumn{7}{|l|}{ History of psychiatric disorder } \\
\hline Yes & 28 & 8 & 15 & 7 & 43 & 7.6 \\
\hline No & 323 & 92 & 200 & 93 & 523 & 92.4 \\
\hline \multicolumn{7}{|l|}{ History of psychiatric disorder in family } \\
\hline Yes & 2 & 0.6 & 2 & 0.9 & 4 & 0.7 \\
\hline No & 349 & 99.4 & 213 & 99.1 & 562 & 99.3 \\
\hline \multicolumn{7}{|l|}{ Social Support } \\
\hline Sufficient social support & 168 & 47.9 & 109 & 50.7 & 277 & 48,9 \\
\hline Poor social support & 183 & 52.1 & 106 & 49.3 & 289 & 51.1 \\
\hline \multicolumn{7}{|l|}{ Psychiatric Treatment Recommendation } \\
\hline Medication & 207 & 59 & 152 & 70.7 & 359 & 63.4 \\
\hline Medication + psychotherapy & 85 & 24.2 & 30 & 14 & 115 & 20.3 \\
\hline Psychotherapy & 49 & 14 & 26 & 12.1 & 75 & 13.2 \\
\hline Follow-up without medication & 10 & 2.8 & 5 & 2.3 & 15 & 2.7 \\
\hline Directing to the Alcohol Substance unit & - & - & 2 & 0.9 & 2 & 0.4 \\
\hline
\end{tabular}

women with breast cancer who presented to our department was high. It is known that women with breast cancer may experience intense psychological difficulties caused by the negative mental effects of the disease itself and the treatment processes including surgery, chemotherapy, hormone therapy or radiotherapy [21, 22]. Another explanation may be that the women are more inclined to express their problems and are keener to seek psychiatric help, whereas men suppress their emotions more and therefore abstain from seeking psychological help. It has been reported that women seek more help among patients with cancer who are followed up in outpatient departments [23]. In traditional Turkish society, men feel that they are meant to present a strong/resistant image, which may have restricted male patients from expressing emotions and seeking help. The reason why the mean age of the women was significantly lower than for male patients may be due to the fact that women with breast cancer comprise a large portion of the population presenting to our department (Table 1 ). It has been reported that $61.5 \%$ of women with breast cancer were aged between 19 and 54 years in Turkey [24].
Of the help-seeking patients with cancer who presented to our department, $97.5 \%$ received psychiatric diagnoses, which is very high compared with the $59.6 \%$ reported in the literature [10]. The high rate of psychiatric diagnoses may be due to the fact that the patients referred to our department already had noticeable psychological problems, which means that they should have sought help earlier. The main reason for patients with cancer withholding their depression and anxiety during oncology visits is that they want to spend their limited time talking about the important issues associated with their illnesses [25]. Therefore, oncologists should inquire into the emotional status of patients, even if they do not mention any psychological challenges.

Another reason for delaying seeking help may be that they suppose they can cope with their psychological problems on their own. Clover et al. (2015) reported that $46 \%$ of patients with psychological distress had no help for treatment because they preferred to manage the process themselves [23]. Prejudice against receiving psychiatry or psychology treatment can be a major source of resistance 
Table 3 Risk factors for mood disorders, adjustment disorders, and anxiety disorders

\begin{tabular}{|c|c|c|c|c|c|c|}
\hline & & B & $p$ & OR & $95 \% \mathrm{Cl}$ & \\
\hline & & & & & Lower & Upper \\
\hline Mood disorders & Marital status (Married/not married) & -0.849 & 0.014 & 2.08 & 0.218 & 0.841 \\
\hline & Education level ( $\leq 8$ years / > 8 years) & 0.679 & 0.045 & 1.97 & 1.014 & 3.839 \\
\hline & Income level (Low/Middle or upper) & -1.485 & 0.003 & 4.41 & 0.089 & 0.609 \\
\hline & Social Support (Poor/Sufficient) & -1.043 & 0.002 & 2.84 & 0.183 & 0.679 \\
\hline & Recurence (No/Yes) & -3.679 & $<0.001$ & 40 & 0.010 & 0.066 \\
\hline & Metastasis (No/Yes) & -1.344 & 0.007 & 3.83 & 0.098 & 0.693 \\
\hline & Secondary cancer (No/Yes) & -2.310 & 0.001 & 10.1 & 0.026 & 0.376 \\
\hline & Other medical illnesses (No/Yes) & -1.511 & $<0.001$ & 4.52 & 0.117 & 0.417 \\
\hline & History of psychiatric disorder (No/Yes) & -1.788 & $<0.001$ & 5.99 & 0.075 & 0.373 \\
\hline & Constant & 7.291 & $<0.001$ & 146.7 & & \\
\hline & Nagelkerke $R^{2}$ & 0.571 & & & & \\
\hline Adjustment Disorders & Marital status (Not married/Married) & -0.464 & 0.050 & 1.59 & 0.394 & 1.003 \\
\hline & Income level (Low/Middle-upper) & -1.256 & $<0.001$ & 3.86 & 0.141 & 0.476 \\
\hline & Social Support (Poor/Sufficient) & -0.452 & 0.030 & 1.57 & 0.424 & 0.957 \\
\hline & Duration of illnesses (0-12 / $\geq 13$ months) & 0.706 & 0.001 & 2.03 & 1.300 & 3.156 \\
\hline & Metastasis (No/Yes) & -0.870 & 0.002 & 2.39 & 0.243 & 0.721 \\
\hline & Recurence (No/Yes) & 1.256 & $<0.001$ & 3.51 & 0.142 & 0.573 \\
\hline & Cancer history in family members (No/Yes) & -0.766 & 0.015 & 2.15 & 0.250 & 0.863 \\
\hline & Other medical illnesses (No/Yes) & -0.696 & 0.005 & 2.01 & 0.307 & 0.807 \\
\hline & History of psychiatric disorder (No/Yes) & -1.431 & $<0.001$ & 4.18 & 0.126 & 0.455 \\
\hline & Constant & 9.631 & $<0.001$ & 152.3 & & \\
\hline & Nagelkerke $\mathrm{R}^{2}$ & 0.276 & & & & \\
\hline Anxiety Disorders & Income level (Low/Middle-upper) & 0.954 & 0.001 & 2.6 & 1.462 & 4.609 \\
\hline & Social Support (Poor/Sufficient) & 0.621 & 0.003 & 1.86 & 1.234 & 2.808 \\
\hline & Duration of illnesses (0-12 / $\geq 13$ months) & 0.504 & 0.02 & 1.65 & 1.081 & 2.533 \\
\hline & Recurence (No/Yes) & 1.884 & $<0.001$ & 6.58 & 3.065 & 14.14 \\
\hline & Secondary cancer (No/Yes) & 1.632 & 0.01 & 5.11 & 1.470 & 17.79 \\
\hline & Other medical illnesses (No/Yes) & 0.631 & 0.011 & 1.88 & 1.155 & 3.06 \\
\hline & History of psychiatric disorder (No/Yes) & 1.202 & $<0.001$ & 3.32 & 1.743 & 6.345 \\
\hline & Constant & -11.35 & $<0.001$ & 128.3 & & \\
\hline & Nagelkerke $\mathrm{R}^{2}$ & 0.295 & & & & \\
\hline
\end{tabular}

in our culture. From the point of view of patients, prejudices such as "only insane people receive treatment from psychiatrists or psychologists" may prevent them from receiving help for psychological problems. At the same time, from the standpoint of physicians, the concern that patients may react negatively to referral to psycho-oncology department may prevent physicians from referring them. As reported in the literature, cultural barriers to which patients are exposed, which impede oncologists' referral of patients to seek help for mental health, should not outweigh the seriousness of psychological problems [26]. The lack of knowledge of how to approach psychological problems, whether there is a real problem experienced by the patient, and the workload and time limitations of oncology staff are among the most important discouraging factors $[27,28]$.

When examining the charts of patients, we noticed that oncologists directed the majority of the patients to the outpatient department of psycho-oncology (Table 2). Mackenzie et al. (2015) support our findings, that the majority of patients with cancer choose to report their concerns and depression to their medical practitioners [25]. Informing physicians about psycho-oncology practices and maintaining active cooperation in oncology is 
Table 4 Risk factors according to sex for mood disorders, adjustment disorders, and anxiety disorders

\begin{tabular}{|c|c|c|c|c|c|c|c|c|c|c|c|}
\hline & & \multicolumn{5}{|l|}{ Female } & \multicolumn{5}{|l|}{ Male } \\
\hline & & \multirow[b]{2}{*}{ B } & \multirow[b]{2}{*}{$p$} & \multirow[b]{2}{*}{ OR } & \multicolumn{2}{|c|}{$95 \% \mathrm{Cl}$ for $\mathrm{OR}$} & \multirow[b]{2}{*}{ B } & \multirow[b]{2}{*}{ p } & \multirow[b]{2}{*}{ OR } & \multicolumn{2}{|c|}{$95 \% \mathrm{Cl}$ for $\mathrm{OR}$} \\
\hline & & & & & Lower & Upper & & & & Lower & Upper \\
\hline \multirow[t]{9}{*}{ Mood disorders } & Income level (Low/Middle- upper) & -1.064 & 0.042 & 2.90 & 0.123 & 0.964 & -2.592 & 0.035 & 13.3 & 0.07 & 0.836 \\
\hline & Social Support (Poor/Sufficient) & -0.935 & 0.013 & 2.54 & 0.188 & 0.819 & -1.771 & 0.022 & 5.88 & 0.04 & 0.771 \\
\hline & Metastasis (No/Yes) & - & - & - & - & - & -2.842 & 0.050 & 17.2 & 0.03 & 0.997 \\
\hline & Recurence (No/Yes) & -3.441 & $<0.001$ & 31.25 & 0.011 & 0.092 & -5.495 & $<0.001$ & 250 & 0.01 & 0.065 \\
\hline & Secondary cancer (No/Yes) & -1.940 & 0.030 & 6.94 & 0.025 & 0.827 & -3.445 & 0.011 & 31.25 & 0.02 & 0.451 \\
\hline & Other medical illnesses (No/Yes) & -0.984 & 0.009 & 2.67 & 0.178 & 0.785 & -2.698 & $<0.001$ & 14.92 & 0.018 & 0.257 \\
\hline & History of psychiatric disorder (No/Yes) & -1.560 & 0.001 & 4.76 & 0.083 & 0.530 & -2.135 & 0.017 & 8.47 & 0.021 & 0.679 \\
\hline & Constant & 5.703 & $<0.001$ & 299.8 & & & 9.888 & $<0.001$ & 1970 & & \\
\hline & Nagelkerke $\mathrm{R}^{2}$ & 0.475 & & & & & 0.714 & & & & \\
\hline \multirow[t]{10}{*}{ Adjustment Disorders } & Education level ( $\leq 8$ years/ > 8 years) & - & - & - & - & - & -1.017 & 0.016 & 2.76 & 0.158 & 0.830 \\
\hline & Income level (Low/Middle- upper) & 0.902 & 0.009 & 2.46 & 1.245 & 4.841 & 2.517 & $<0.001$ & 12.39 & 3.146 & 4.78 \\
\hline & Social Support (Poor/Sufficient) & 0.537 & 0.034 & 1.71 & 1.042 & 2.806 & - & - & - & - & - \\
\hline & Metastasis (No/Yes) & - & - & - & - & - & - & - & - & - & - \\
\hline & Recurence (No/Yes) & 1.220 & 0.003 & 3.38 & 1.494 & 7.682 & 2.153 & 0.007 & 8.61 & 1.812 & 4.94 \\
\hline & Other medical illnesses (No/Yes) & 0.783 & 0.006 & 2.19 & 1.247 & 3.842 & - & - & - & - & - \\
\hline & Cancer history in family members (No/Yes) & - & - & - & - & - & -1.668 & 0.032 & 5.29 & 0.041 & 0.870 \\
\hline & History of psychiatric disorder (No/Yes) & 1.212 & 0.003 & 3.36 & 1.518 & 7.440 & 1.459 & 0.017 & 4.303 & 1.302 & 4.219 \\
\hline & Constant & -2.808 & 0.005 & 16.6 & & & -2.669 & 0.007 & 8.92 & & \\
\hline & Nagelkerke $\mathrm{R}^{2}$ & 0.199 & & & & & 0.376 & & & & \\
\hline \multirow[t]{9}{*}{ Anxiety Disorders } & Income level (Low/Middle- upper) & -0.767 & 0.027 & 2.15 & 0.235 & 0.918 & -0.767 & 0.027 & 2.15 & 0.235 & 0.918 \\
\hline & Social Support (Poor/Sufficient) & -0.645 & 0.014 & 1.9 & 0.314 & 0.876 & - & - & - & - & - \\
\hline & Metastasis (No/Yes) & -0.893 & 0.021 & 2.43 & 0.192 & 0.876 & - & - & - & - & - \\
\hline & Recurence (No/Yes) & -2.052 & $<0.001$ & 7.81 & 0.048 & 0.343 & -1.691 & 0.028 & 5.43 & 0.41 & 0.832 \\
\hline & Secondary cancer (No/Yes) & -1.502 & 0.048 & 4.06 & 0.049 & 1.229 & -2.585 & 0.031 & 13.33 & 0.07 & 0.789 \\
\hline & Other medical illnesses (No/Yes) & -0.643 & 0.034 & 1.09 & 0.290 & 0.951 & - & - & - & - & - \\
\hline & History of psychiatric disorder (No/Yes) & -1.502 & 0.001 & 4.48 & 0.095 & 0.520 & - & - & - & - & - \\
\hline & Constant & 5.591 & $<0.001$ & 167.84 & & & 3.737 & 0.01 & 41.97 & & \\
\hline & Nagelkerke $\mathrm{R}^{2}$ & 0.280 & & & & & 0.316 & & & & \\
\hline
\end{tabular}

OR Odds ratios

$\mathrm{Cl}$ Confidence Intervals

important in terms of providing mental health services more effectively.

The symptoms that lead patients to our outpatient department include sleep problems, irritability, tendency to cry easily, depression, and pain (not compatible with the medical condition) (Table 2). Women reported sleeping problems, tendency to cry easily, irritability, pre-occupation with illness, and despondency as the most frequent symptoms, and men reported sleep problems, irritability, pain, despondency, and a tendency to cry easily (Table 2). Sleep problems were noted to be the most prominent symptoms of depression, adjustment disorders, and anxiety; the rate of patients with cancer diagnosed as having insomnia only is reported as high as 30-60\% [28, 29].
The distribution of the prevalence of psychiatric diagnoses was as follows: adjustment disorder (65\%), and mood disorders (18\%) (e.g. major depression, bipolar disorder, complicated mourning), anxiety disorders (9.7\%), organic brain syndrome $(1.4 \%)$, personality disorder $(1.4 \%)$, delusional disorder $(1.2 \%)$, and insomnia $(0.9 \%)$, as well as comorbidities (depression associated with either generalized anxiety disorder or obsessive compulsive disorder), which is compatible with the results reported in the literature (Table 2). Derogatis et al. stated that $68 \%$ of patients with cancer had adjustment disorder, 13\% major depression, $8 \%$ organic brain syndrome (OBS), $7 \%$ personality disorder, and $4 \%$ pre-existing anxiety disorder [7]. Adjustment disorders in patients with cancer have been reported 
as $55.8 \%$ in Turkey [30]. Patients with cancer have 10 $25 \%$ major depression and clinically significant depressive symptoms at similar rates $[17,30]$. Tokgöz et al. found that depression prevalence was $22 \%$ in patients with cancer and sleep problems were frequent [31]. The fact that we reported a small number of patients with OBS might be due to (i) the study covered only outpatient patients who actively sought help (ii) patients with OBS usually present to the emergency department of psychiatry.

According to the results of the regression analysis, the common risk factors for adjustment disorders, mood disorders, and anxiety disorders were low income level, poor social support, cancer recurrence, other chronic medical illness, and history of psychiatric disorder (Table 3). Our findings are consistent with the risk factors reported for psychiatric disorders in patients with cancer [16, 32, 33]. In this study, the most significant risk factor for all diagnostic groups was the recurrence of cancer; metastasis was not found as a significant risk factor for any of the diagnostic groups. At this point, it is necessary to discuss why disease recurrence has a much greater adverse effect than metastasis on mental health. Burgess et al. found that 222 women with early breast cancer had depression and anxiety disorders at a rate of $33 \%$ during the course of diagnosis, at a rate of $15 \%$ at 1 year, and at a rate of $45 \%$ during recurrence of diseases [34]. The reason why patients develop depression or anxiety upon learning about the recurrence of cancer may arise from experience of former therapeutic processes (chemotherapy, radiotherapy or surgery), which is not surprising. We think that metastasis was not such a significant factor for all three diagnostic groups because the patients might be unaware of metastasis or what metastasis means or were not informed about metastasis. This is because medical professionals do not have to legally inform patients about the diagnosis and disease progression, and sometimes the family does not want the patient to be informed about the cancer in order to protect the patient $[35,36]$.

Our findings are consistent with the literature in that the risk for adjustment disorder and anxiety disorders increases when the patients receive cancer diagnosis, particularly in the first year [37]. There were no differences in risk factors for any psychiatric diagnoses with respect to age and sex in our study. In contrast to our findings, some studies have reported a significant sex or age difference in the cancer population $[31,38,39]$, but there are findings compatible with ours in the medical literature $[40,41]$. Age and sex might not seem to have been significant risk factors in our study because it included patients with a wide range of cancer types and stages.

When we examined the risk factors in terms of sex in the psychiatric diagnosis groups, it was determined that disease recurrence, history of psychiatric disorder, and low income level were common risk factors for both men and women. The presence of other chronic medical illnesses and poor social support, which were found as significant risk factors for the three diagnostic groups, were identified as leading significant risk factors for women. Metastasis was identified as a significant risk factor for anxiety disorders in women and for mood diagnoses in men. As seen, the risk factors determined for the overall patient population and the risk factors determined on the basis of sex are similar in many respects but differ in some points (Table 4). Our study describes a large number of patients seeking help for mental health with various types of cancer in terms of sociodemographic characteristics, disease characteristics, and psychiatric characteristics. More importantly, it draws a profile of risk factors for severe mental problems that we encountered in both overall risk factors and sex-related risk factors in patients with cancer seeking help for mental health. In addition, the generalizability of the data obtained in the regression analysis is very high - approximately $50 \%$ in women, $70 \%$ in men - for mood disorders.

\section{Clinical implications}

This paper gives a clear picture of patients with cancer who seek help for mental health by presenting information on characteristics (sociodemographic, cancer-related, and psychiatric), the prevalence of mental disorders, as well as risk factors for mood disorders, adjustment disorders, and anxiety disorders. When there is a delay - for whatever reason - in seeking help for mental health, undesirable consequences such as increased morbidity, noncompliance with treatment, increasing mortality may appear [41]. Based on this evidence, the fact that $97.5 \%$ of our patients received diagnoses of psychiatric disorders shows how valuable early referral could be. Our study will also contribute to raising oncologists' awareness toward the various risk factors, thus more patients at risk for mental disorders can be identified by oncologists and more patients may gain access to mental health care earlier.

Our study results involve all types and stages of cancers and both sexes; therefore, they could be used in developing and planning effective psycho-oncology services and guide research in the field of psycho-oncology. Additionally, the study raises questions that draw attention to patients' mental distress in oncology practice:

1. What are the characteristics of patients who do not seek/ demand help but are at a high risk for mental health problems?

2. What are the potential drawbacks of patients with cancer seeking help in terms of the patients themselves, environmental and contextual, and how can we handle such challenges? 
3. How can psycho-oncology services be further improved to be extended to patients with cancer in general?

\section{Study strengths and limitations}

This study has some strengths and limitations. One of the strengths was that our sample consisted of patients with cancer with various stages and types of disease who presented to the outpatient psycho-oncology clinic, thus not focusing on patients with a single cancer type or stage. Our study reflects the data on outpatient patients with cancer who were referred to seek help for mental health and actively complied with the recommendations of their doctors. One limitation of the study is that it is an exploratory study with a retrospective chart review design. Another is the lack of assessment of important psychological aspects, such as coping styles and quality of life. A further limitation is that, although DSM-IV-TR diagnostic criteria were used for diagnostic evaluation, the possibility of individual differences of practitioners could not be completely excluded. Finally, the study does not reflect inpatient data because it is limited to patients who were referred to the psycho-oncology outpatient clinic.

\section{Conclusion}

This study identifies the distribution of psychiatric disorders, the risk factors for specific psychiatric disorders, and draws attention to the fact that there are serious delays in patients seeking psychiatric help and in the referrals of oncologists for psychological assessment. Identifying risk factors and raising oncologists' awareness toward risk factors could help more patients gain access to mental health care much earlier. In addition, media institutions can be supported to overcome social prejudices about the need for psychological help and to raise public awareness of the psychological problems that arise in cancer. These may increase the number of patients who become aware of psychological problems and seeking help for mental help.

\section{List of abbreviations}

C.I.: Confidence Intervals; CLP: Consultation Liaison Psychiatry; DSM-IV-

TR: Statistical Manual of Mental Disorders, 4th Edition; OR: Odds ratios

\section{Acknowledgements}

None.

\section{Authors' contributions}

DA participated in the conception and design of the study, analysis, and interpretation of data and wrote the manuscript. MÖ contributed to the acquisition of data and the critical revision of the manuscript. SÖ participated in the conception and design of the study, in the interpretation of data and in the critical revision of the manuscript. AK participated in the conception and design of the study, and critical revision of the manuscript. All authors give final approval of the manuscript submitted.

\section{Funding}

No intitution had funded the study.

\section{Availability of data and materials}

The patient cards used in the study can not be shared with other researchers because they contain personal information (the identification number, the birth date etc.). The data sets used and analyzed during the current study are available from the corresponding author on reasonable request and with consent from the Institutional Review Board (IRB).

\section{Ethics approval and consent to participate}

The study was reviewed and approved by the institutional review boards at Oncology Institute of Istanbul University in terms of ethic (no: 709731125604.01.01) on 5 February 2018. Because the study is a retrospective one and we only reviewed the charts of the patients and we made neither interviews nor evaluations with the patients to perform the study it wasn't necessary to get written consent from the patients. All patients' records were anonymized and de-identified prior to analyses.

\section{Consent for publication}

Not applicable

\section{Competing interests}

The authors declare that they have no competing interests.

\section{Author details}

'Department of Consultation Liaison Psychiatry, Department of Psychiatry, Istanbul Faculty of Medicine, Istanbul University, Capa, 34390 Istanbul, Turkey. ${ }^{2}$ Department of Radiation Oncology, Institute of Oncology, Istanbul University, 34390 Istanbul, Capa, Turkey.

Received: 4 December 2018 Accepted: 22 August 2019

Published online: 03 September 2019

\section{References}

1. World Health Organization. The Global Burden of Disease: 2004 Update. Geneva: World Health Organisation; 2008.

2. Boyle P, Levin B. World Cancer report 2008. IARC Press, International Agency for Research on Cancer; 2008.

3. Lederberg MS. Psychooncology. In Kaplan \& Sadock's Comprehensive Textbook of Psychiatry, 8th edition. (Eds. BJ Sadock, VA Sadock):2196-2225. Philadelphia: Lippincott Williams \& Wilkins; 2005.

4. Zabora J, BrintzenhofeSzoc K, Curbow B, Hooker C, Piantadosi S. The prevalence of psychological distress by cancer site. Psychooncology. 2001; 10(1):19-28.

5. Bultz BD, Holland JC. Emotional distress in patients with cancer: the sixth vital sign. Community Oncol. 2006;3(5):311-4.

6. Holland JC, Andersen B, Breitbart WS, et al. Distress management. J Natl Compr Cancer Netw. 2010;8(4):448-85.

7. Derogatis $L R$, Morrow GR, Fetting J, et al. The prevalence of psychiatric disorders among Cancer patients. JAMA. 1983;249(6):751.

8. Chahl P, Bond A. "I"m sorry but you've got cancer': the role of psychooncology. Br J Hosp Med. 2009;70(9):514-7.

9. Breitbart W. Identifying patients at risk for, and treatment of major psychiatric complications of cancer. Support Care Cancer. 1995;3(1):45-60.

10. Tada Y, Matsubara M, Kawada S, et al. Psychiatric disorders in Cancer patients at a University Hospital in Japan: descriptive analysis of 765 psychiatric referrals. Jpn J Clin Oncol. 2012;42:183-8.

11. Levine PM, Silberfarb PM, Lipowski ZJ. Mental disorders in cancer patients. A study of 100 psychiatric referrals. Cancer. 1978;42(3):1385-91.

12. Razavi D, Stiefel F. Common psychiatric disorders in cancer patients. Support Care Cancer. 1994;2(4):223-32.

13. Kissane DW, Smith GC. Consultation-liaison psychiatry in an Australian oncology unit. Aust New Zeal J Psychiatry. 1996;30(3):397-404.

14. Massie MJHJ. Psycho-oncology: overview of normal reactions and prevalence of psychiatric disorders. 2nd ed. New York: Oxford University Press; 1998.

15. Loberiza FR, Rizzo JD, Bredeson CN, et al. Association of depressive syndrome and early deaths among patients after stem-cell transplantation for malignant diseases. J Clin Oncol. 2002;20(8):2118-26.

16. Breitbart W, Rosenfeld B, Pessin H, et al. Depression, hopelessness, and desire for hastened death in terminally ill patients with Cancer. JAMA. 2000; 284(22):2907. 
17. Valdimarsdó U, Helgason R, Fü Rst C-J, Adolfsson J, Steineck G. The unrecognised cost of cancer patients' unrelieved symptoms: a nationwide follow-up of their surviving partners. Br J Cancer. 2002;86:1540-5.

18. Kurtz ME, Kurtz JC, Given CW, Given B. Relationship of caregiver reactions and depression to cancer patients' symptoms, functional states and depression-a longitudinal view. Soc Sci Med. 1995;40(6):837-46.

19. Holland JC. IPOS Sutherland memorial lecture: an international perspective on the development of psychosocial oncology: overcoming cultural and attitudinal barriers to improve psychosocial care. PsychoOncology. 2004;13: 445-59.

20. American Psychiatric Association. Diagnostic and statistical manual: mental disorders: DSM-IV-TR. Washington DC: American Psychiatric Press; 2000.

21. Capuron L, Ravaud A, Dantzer R. Early depressive symptoms in cancer patients receiving interleukin 2 and/or interferon alfa-2b therapy. J Clin Oncol. 2000;18(10):2143-51.

22. Ganz PA. Impact of tamoxifen adjuvant therapy on symptoms, functioning, and quality of life. JNCI Monographs. 2001;2001(30):130-34.

23. Clover KA, Mitchell AJ, Britton B, Carter G. Why do oncology outpatients who report emotional distress decline help? Psychooncology. 2015;24(7): 812-8.

24. Özmen V. Türkiye'de Meme Kanseri (Breast Cancer in Turkey). Turkiye Klin J Gen Surg Spec Top. 2013;6(2):1-6.

25. Mackenzie LJ, Carey M, Sanson-Fisher R, D'Este C, Yoong SL. A crosssectional study of radiation oncology outpatients' concern about, preferences for, and perceived barriers to discussing anxiety and depression. Psychooncology. 2015;24(11):1392-7.

26. Dilworth S, Higgins I, Parker V, Kelly B, Turner J. Patient and health professional's perceived barriers to the delivery of psychosocial care to adults with cancer: a systematic review. Psychooncology. 2014;23(6):601-12.

27. Breitbart WS, Alici Y. Psycho-oncology. Harv Rev Psychiatry. 2009;17(6):361-76.

28. Herschbach P. Behandlungsbedarf in der Psychoonkologie. Der Onkol. 2006; 12(1):4-7.

29. Sharma $\mathrm{N}$, Hansen $\mathrm{CH}, \mathrm{O}^{\prime}$ Connor $\mathrm{M}$, et al. Sleep problems in cancer patients: prevalence and association with distress and pain. Psychooncology. 2012; 21(9):1003-9.

30. Ç Ateşci F, Oğuzhanoğlu NK, Baltalarli B, Karadağ F, Özdel O, Karagöz N. Kanser Hastalarında Psikiyatrik Bozukluklar ve Illişkili Etmenler. Türk Psikiyatr Derg 2003;14(2):145-152

31. Nelson CJ, Cho C, Berk AR, Holland J, Roth AJ. Are gold standard depression measures appropriate for use in geriatric cancer patients? A systematic evaluation of self-report depression instruments used with geriatric, cancer, and geriatric cancer samples. J Clin Oncol. 2010;28(2):348-56.

32. Tokgöz G, Yaluğ I, Özdemir S. Kanser hastalarında majör depresyon yaygınlığı ve ilişkili etkenler. Anadolu Psikiyatri Dergisi. 2008;9:56-66.

33. Berard RM. Depression and anxiety in oncology: the psychiatrist's perspective. J Clin Psychiatry. 2001;62(Suppl 8):58-61 3

34. Weiss Wiesel TR, Nelson CJ, Tew WP, et al. The relationship between age, anxiety, and depression in older adults with cancer. Psychooncology. 2015; 24(6):712-7.

35. Burgess C, Cornelius V, Love S, Graham J, Richards M, Ramirez A. Depression and anxiety in women with early breast cancer: five year observational cohort study. BMJ. 2005;330(7493):702.

36. Shahidi J. Not telling the truth: circumstances leading to concealment of diagnosis and prognosis from cancer patients. Eur J Cancer Care. 2010;19: 589-93.

37. Kazdaglis GA, Arnaoutoglou C, Karypidis D, Memekidou G, Spanos G, Papadopoulos O. Disclosing the truth to terminal cancer patients: a discussion of ethical and cultural issues. East Mediterr Health J. 2010;16:442-7.

38. Kocaman Yıldırım N, Özkan M, Özkan S, Özçinar B, Güler SA, Özmen V. Meme kanserli hastalarin tedavi öncesi ve sonrasi anksiyete, depresyon ve yaşam kalitesi: Bir yillik prospektif değerlendirme sonuçlari. Noropsikiyatri Arşivi. 2009;46(4):175-81.

39. Linden W, Vodermaier A, Mackenzie R, Greig D. Anxiety and depression after cancer diagnosis: prevalence rates by cancer type, gender, and age. J Affect Disord. 2012;141:343-51.
40. Nipp RD, Greer JA, El-Jawahri A, et al. Age and gender moderate the impact of early palliative Care in Metastatic non-Small Cell Lung Cancer. Oncologist. 2016;21(1):119-26

41. Daniel Carr I, Goudas L, Lawrence D, et al. Evidence report /technology assessment Management of Cancer Symptoms: pain, depression, and fatigue. 2002.

\section{Publisher's Note}

Springer Nature remains neutral with regard to jurisdictional claims in published maps and institutional affiliations.
Ready to submit your research? Choose BMC and benefit from:

- fast, convenient online submission

- thorough peer review by experienced researchers in your field

- rapid publication on acceptance

- support for research data, including large and complex data types

- gold Open Access which fosters wider collaboration and increased citations

- maximum visibility for your research: over $100 \mathrm{M}$ website views per year

At BMC, research is always in progress.

Learn more biomedcentral.com/submissions 